\title{
Application of an atmospheric boundary layer model to a large-scale coupled sea-ice-oceanic mixed-layer model for the Southern Ocean
}

\author{
ACHIM STÖSSEL \\ Max-Planck-Institut für Meteorologie, Bundesstrasse 55, 2000 Hamburg 13, Germany
}

\begin{abstract}
A coupled sea-ice-oceanic mixed-layer model for the Southern Ocean is forced with daily atmospheric variables from the global analyses of the European Center for Medium Range Weather Forecasts (ECMWF). Using the analyses of the lowest level in the calculations of the turbulent heat fluxes and stresses with the appropriate bulk formulae, the simulation results resemble earlier ones with climatological forcing. In order to avoid a predetermination of the simulated sea-ice conditions from the (climatological) specification of the surface boundary conditions in the atmospheric general circulation model (AGCM), the sea-ice model is coupled additionally to a one-dimensional atmospheric boundary layer model. Using the global ECMWF-analyses as before, the coupled model is now forced from the geostrophic level $(850 \mathrm{hPa})$. Without any changes of the original model parameters and physics, the results are rather poor in that the ice extent as well as the ice velocities are generally too low and that the ice thickness distribution resembles the results of a pure thermodynamic sea-ice model. The results with the forcing from the higher level are more realistic when snow and mixed-layer effects are neglected, thus resembling those of Koch (1988) in the Weddell Sea. This indicates that the parameterizations in the atmospheric boundary layer model have to be readjusted in order to interact realistically with the snow-sea-ice-oceanic mixed-layer model. Additionally, it will be demonstrated that the pattern of the wind field, whether from the geostrophic or the surface level, has a significant influence on the sea-ice model results.
\end{abstract}

\section{INTRODUCTION}

One of the major problems in sea-ice modelling is the high sensitivity of the model results to the prescribed forcing, in particular to oceanic heat flux and wind. The quality of the model results is, therefore, highly dependent on the quality of the forcing fields. Since the Southern Ocean area is probably the one with the coarsest observation net on Earth, one can expect that errors in the forcing fields may be at least as important as model errors.

In order to avoid the specification of an oceanic heat flux, the sea-ice (SI) model of Hibler and Ackley (1983) has been coupled to a one-dimensional oceanic mixedlayer (OML) model (Lemke and others, 1990; Owens and Lemke, 1990).

Similarly, the atmospheric forcing was determined inter-actively by coupling the same SI model to a onedimensional atmospheric boundary-layer (ABL) model, where the forcing has been raised to the geostrophic level (Koch, 1988).

In this paper, the influence of the coupling of the SI model alternatively to the OML and $\mathrm{ABL}$ models will be investigated and is, in the following, presented in a hierarchy of coupling schemes. The influence of the wind forcing from a different level is shown in a final sensitivity experiment.

\section{THE SI-OML MODEL}

The coupled SI-OML model from Lemke and others (1990) and Owens and Lemke (1990) has been applied to the entire Southern Ocean region (Stössel and others, 1990). The SI model is based on Hibler (1984), with an additional continuity equation for the snow thickness (Owens and Lemke, 1990). The OML model is onedimensional and incorporates an exponentially shaped pycnocline (Lemke, 1987). The model is run on a spherical, circumpolar grid with a latitudinal resolution of $2.5^{\circ}$ and a longitudinal resolution of $5^{\circ}$, extending from $50^{\circ}-80^{\circ} \mathrm{S}$, using a daily time step.

The forcing is prescribed in the lowest layer of the atmosphere and at a depth of $500 \mathrm{~m}$ in the ocean. The forcing with respect to the intermediate ocean temperature and salinity, the geostrophic current, the precipitation and the cloudiness is derived from climatologies (Stössel and 
others, 1990). The atmospheric forcing with respect to temperature, humidity and wind, on the other hand, is determined from daily (real-time) computations derived from the global analyses of the ECMWF (Trenberth and Olson, 1988), where the lowest level is described at $1000 \mathrm{hPa}$. To drive the SI-OML model, the wind is taken directly from that level, following Trenberth and others (1989); whereas the temperature and humidity fields above the surface are computed by interpolation between the $850 \mathrm{hPa}$ and the $1000 \mathrm{hPa}$ fields or, if the $1000 \mathrm{hPa}$ level is above the surface, by extrapolation and lapse rate formulation, respectively.

Cyclo-stationarity of the response of ice volume and ice extent is achieved after five years of simulation. The forcing for the first five years of model integration is specified from data analyses for the year 1985, whereas for the sixth year it is transiently given by the data for 1986 .
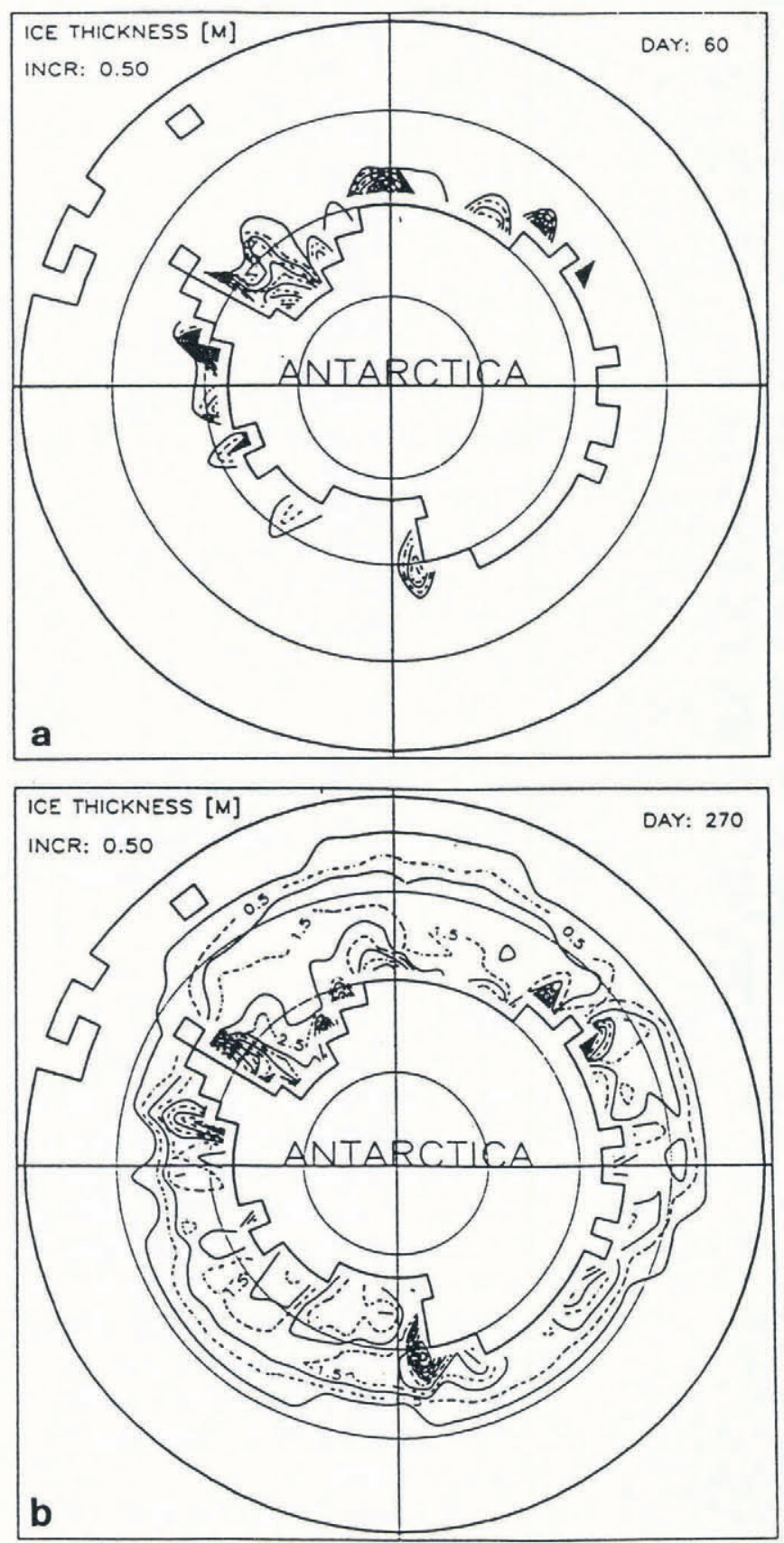

Fig. 1. Ice thickness contours, as simulated by the SI-OML model for the approximate date of (a) minimum (1 March 1986) and (b) maximum (27 September 1986) ice extent.
This final year will be used in the following analyses of the model results.

With this new kind of forcing, the SI-OML model is run without any changes in the model parameters (i.e. ice strength and lead-closing parameter) as well as drag and transfer coefficients relative to the standard version described in Stössel and others (1990). The resulting ice thickness distribution is shown in Figure 1 for the approximate time of minimum (a) and maximum (b) ice extent. Day 60 corresponds to 1 March 1986 and day 270 to 27 September 1986.

Compared to the standard results in Stössel and others (1990), where monthly forcing values from the Taljaard and others (1969) climatology have been employed, the new results with the daily forcing are similar in the Weddell Sea, where the observed characteristic ice thickness pattern is captured by the model. In other
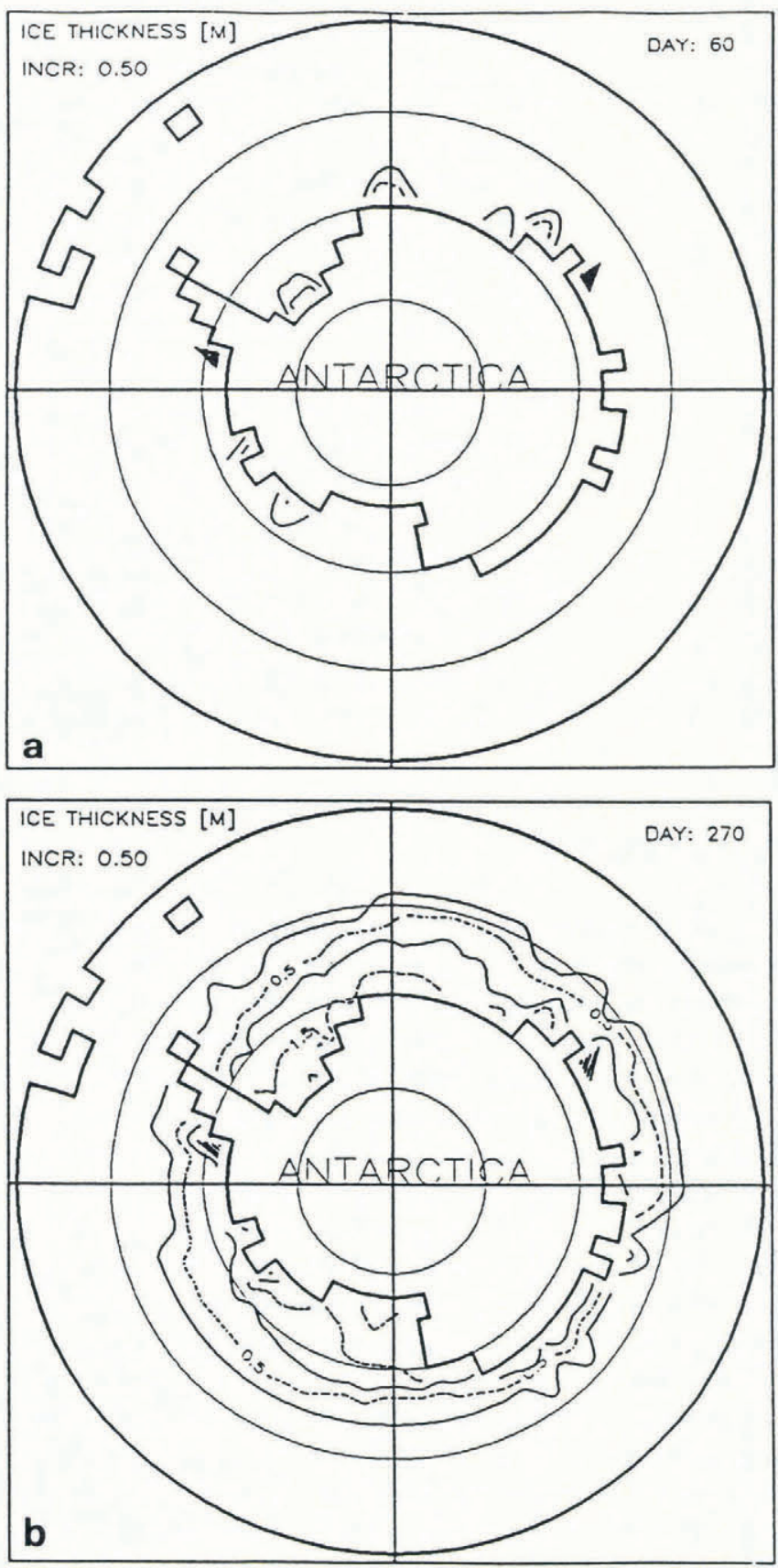

Fig. 2. Ice thickness contours, as simulated by the SI-OML$A B L$ model for the same dates as in Figure 1. 
regions, for example east of Victoria Land and in the Bellingshausen Sea, slight improvements are achieved compared to the previously published results. The main deficiencies compared to observations are a slightly overestimated winter ice extent and a general over-estimation of the compressions in convergent ice areas.

\section{THE SI-OML-ABL MODEL}

Since the network of meteorological observing stations in the Southern Ocean area is rather sparse, the fields of the global analyses consist mainly of model forecast results from the numerical weather prediction (NWP) model of the ECMWF. The NWP model results of the lowest level (especially the air temperature), however, are highly dependent on the specified lower boundary conditions (especially the sea-surface temperature patterns and the sea-ice boundaries). In order to reduce the influence of those conditions (which are primarily climatological) on the sea-ice model results, the forcing level is raised to the next higher level which, in the case of the ECMWF analyses, is the $850 \mathrm{hPa}$ level. This is done by coupling the SI-OML model to the ABL model used by Koch (1988). This model resolves the Prandtl layer with the MoninObukhov theory and the barotropic Ekman layer with the Rossby number similarity theory, both in a vertically integrated form.

The increase of the forcing level concerns the variables temperature, humidity and wind. The sea-level pressure is derived from the same data set in order to determine the potential temperature.

Initially, the SI-OML-ABL model is run without any specific tuning. The resulting ice thickness distribution is shown in Figure 2. The differences compared to the previous results (Fig. 1) are striking: the ice extent is reduced significantly and the ice thickness distribution resembles that of a pure thermodynamic sea-ice model (Stössel and others, 1990). Compared to the results with surface wind forcing (Stössel, 1990) the mean ice velocities are significantly reduced, especially in the Ross Sea (up to $8 \mathrm{~cm} \mathrm{~s}^{-1}$; Fig. 3).

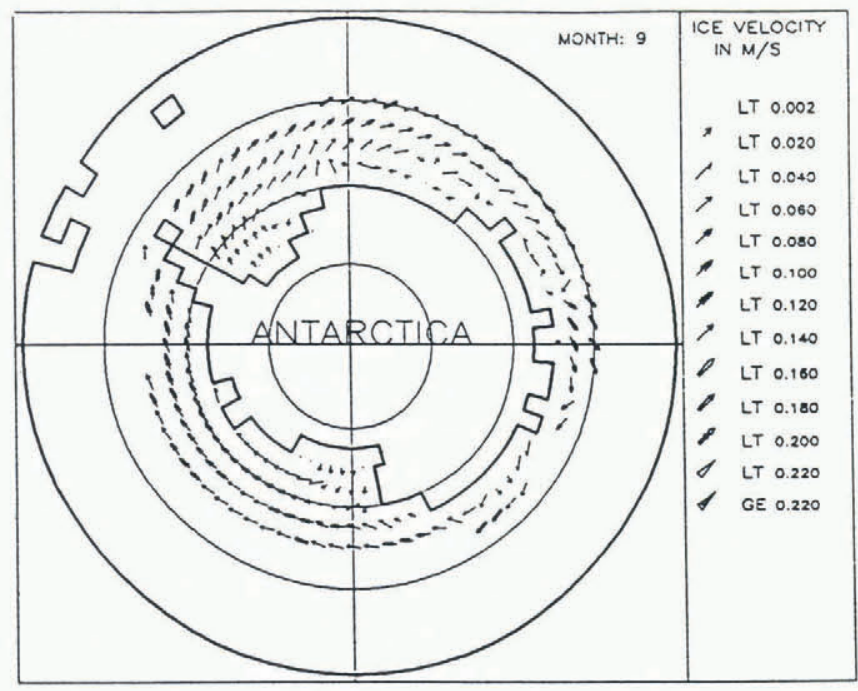

Fig. 3. Mean ice velocities for September 1986, as simulated by the SI-OML-ABL model.
Although the thinner ice thickness compares better with observations (Wadhams and others, 1987), the results are rather unrealistic. Since the ice extent could be described rather well by Koch (1988), with the Hibler and Ackley (1983) sea-ice model for the Weddell Sea, the present model hierarchy will be degraded to that model in the following.

\section{REDUCTION OF THE MODEL PHYSICS}

The essential differences between the present SI-OML model and the sea-ice model of Hibler and Ackley (1983) are the coupling to the OML model and the prognostic simulation of the snow thickness (Owens and Lemke, 1990). Figure 4 demonstrates the effect of neglecting those two processes on the seasonal cycles of ice extent and ice volume. The lower curves ( 1 in Fig. 4 ) show the results of the previous run with the complete SI-OML-ABL model. Neglecting the prognostic determination of the snow cover raises the ice volume by about $2 \times 10^{3} \mathrm{~km}^{3}$ in summer and $4 \times 10^{3} \mathrm{~km}^{3}$ in winter, whereas the ice extent increases only slightly by about $1 \times 10^{6} \mathrm{~km}^{2}(2$ in Fig. 4). This corresponds qualitatively to the results of a similar experiment in Owens and Lemke (1990) and Stössel and others (1990). The quantitative differences can be attributed primarily to the different transfer coefficients of the turbulent heat fluxes, which are determined diagnostically by the friction velocity when coupled to the ABL model.

If, in addition, the OML model is decoupled and, consistent with Hibler and Ackley (1983), a constant

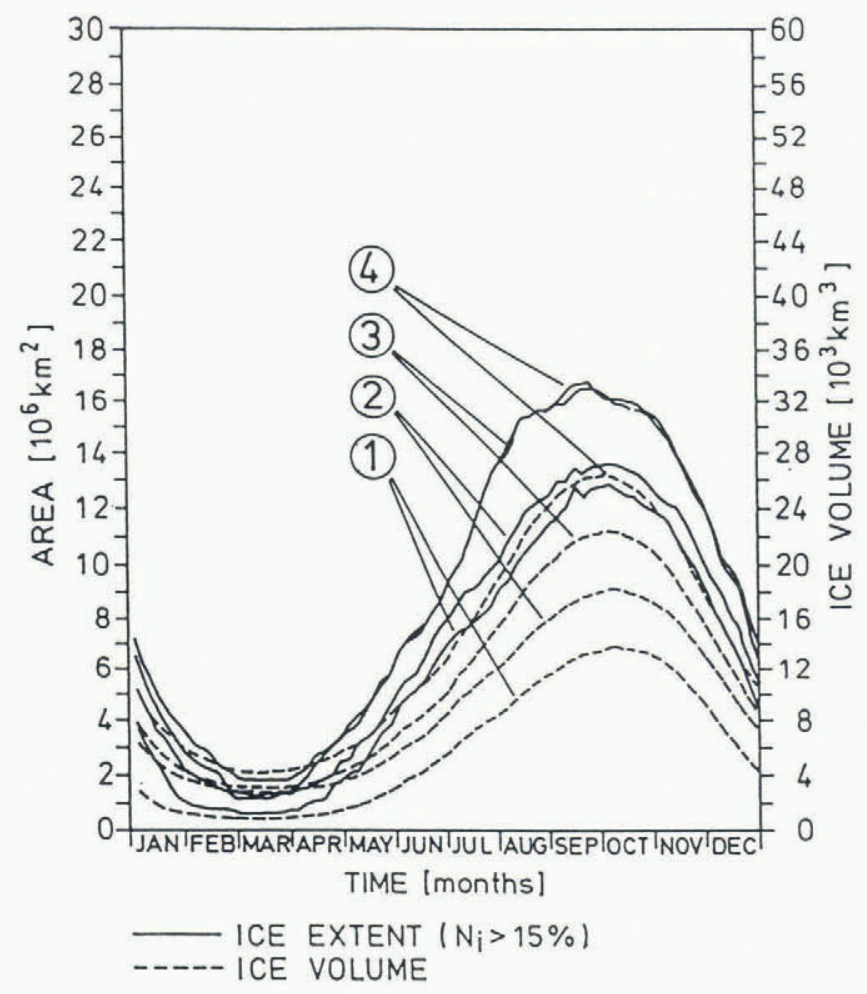

Fig. 4. Seasonal cycles of ice extent and ice volume for the year 1986, as simulated by: (1) the SI-OML-ABL model; (2) the same as (1) without snow; (3) the same as (2) with the OML model decoupled (SI-ABL model); and (4) the same as (3) with higher lead-closing parameter. 
mixed-layer thickness of $30 \mathrm{~m}$ and a constant oceanic heat flux of $2 \mathrm{~W} \mathrm{~m}^{-2}$ is assumed, one achieves the seasonal cycles marked by 3 in Figure 4 . With this modification, the winter maximum ice volume increases by $4 \times 10^{3} \mathrm{~km}^{3}$ and the maximum ice extent by $5.5 \times 10^{6} \mathrm{~km}^{2}$, whereas the summer values remain almost unchanged. The influence of the prognostic mixed layer is relatively large and resembles the corresponding influence on the pure thermodynamic results (Stössel and others, 1990). This indicates that the overall ice drift is also underestimated in the present experiment.

An increase in summer ice extent of about $1 \times 10^{6} \mathrm{~km}^{2}$, and a further increase of the maximum ice volume of about $4 \times 10^{3} \mathrm{~km}^{3}$, can finally be achieved by raising the lead-closing parameter in the sea-ice model
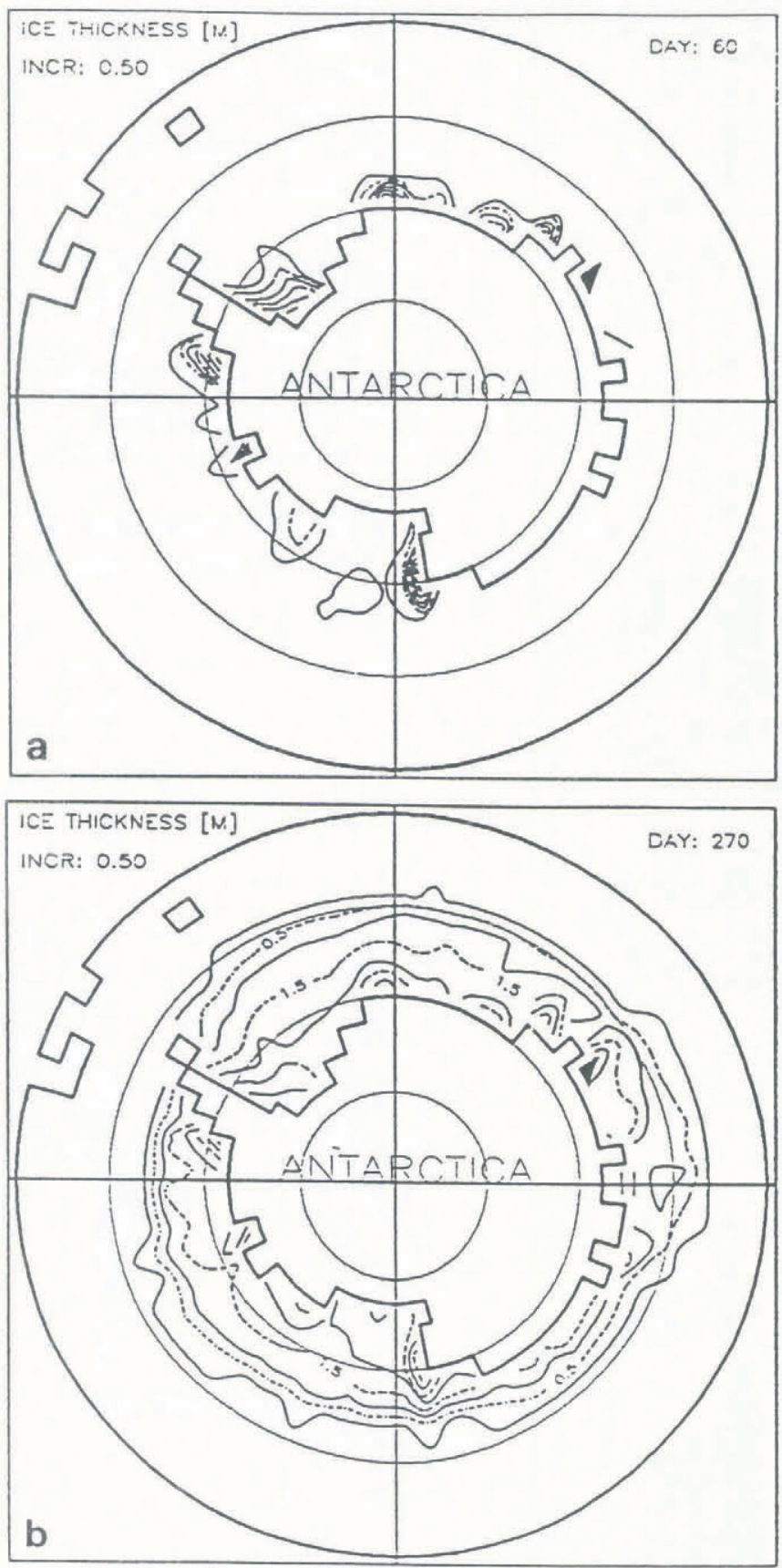

Fig. 5. Ice thickness contours, as simulated by the $S I-A B L$ model neglecting snow, using a higher lead-closing parameter and employing the $1000 \mathrm{hPa}$ wind field instead of the $850 \mathrm{hPa}$ one, for the same dates as in Figure 1. from 0.5 to $1.0 \mathrm{~m}$, as was done by Koch (1988) and Hibler and Ackley (1983). This parameter is empirical, and determines the rate of lateral freezing, with the higher value leading to slower lead closing. As compared to the observed seasonal cycle of ice extent for 1986 (Gloersen and Campbell, 1988), where the minimum is about $3.4 \times 10^{6} \mathrm{~km}^{2}$ and the maximum about $17.7 \times 10^{6} \mathrm{~km}^{2}$, the results with the above modifications have significantly improved (curves labelled 4 in Fig. 4).

\section{SENSITIVITY TO WIND FORCING}

Whereas the latter improvements are valid for the seasonal cycles, this is not the case for the areal ice thickness distribution, which is the most sensitive indicator for incorrect sea-ice simulations. Particular strong ridging of ice occurs at the west coast of the Antarctic Peninsula. This resembles the results with the alternative climatological wind forcing from Hellerman and Rosenstein (1983), shown in Stössel and others (1990), where the wind stress vectors are mostly zonally (eastward) distributed over the entire domain, especially in winter. As can be expected, there is also a more zonal pattern in the $850 \mathrm{hPa}$ wind field of the ECMWF analyses than in the corresponding $1000 \mathrm{hPa}$ field, where the wind field is influenced by the orography.

The ice thickness distribution improves significantly by replacing the $850 \mathrm{hPa}$ winds by those of the $1000 \mathrm{hPa}$ level, keeping the wind turning angle at zero, neglecting snow and mixed-layer effects, and using the higher leadclosing parameter (Fig. 5). Compared to Figure 1, the new results are more realistic in the way that the winter ice extent is lower and the ridging in the convergent ice regimes is much less. Compared to Figure 2, on the other hand, the overall ice extent and ice thickness are largely increased (towards observations) and the pure thermodynamic character of the thickness distribution is replaced by a more dynamic one.

In spite of these improvements, the observed characteristic ice thickness distribution in the Weddell Sea (which might be considered as some kind of reference area for the entire Southern Ocean) is still underdeveloped in this experiment, indicating that the surface drag, which is calculated via the stability dependent friction velocity, is too low.

\section{CONCLUSIONS}

Without any tuning, the SI-OML model forced with daily (real-time) atmospheric variables (temperature, humidity and wind) from the global analyses of the ECMWF instead of monthly (climatological) variables of the Taljaard and others (1969) data set, yields reasonable simulation results. This supports the quality of the $1000 \mathrm{hPa}$ values of the ECMWF analyses. The main deficiency, namely the over-estimated ridging in convergent ice areas, can be improved by either tuning the ice strength parameter of the sea-ice model and simultaneously the drag coefficient for the air/ice stress or by applying an adequate Prandtl-layer formulation similar to that in the ECWMF-AGCM, both of which will be 
demonstrated in a subsequent paper.

The simulation using the SI-OML-ABL model with the above-mentioned forcing variables raised to the $850 \mathrm{hPa}$ level is less successful, unless the snow cover is neglected, the OML model decoupled and the lead-closing parameter increased. Even then the overall ice thickness distribution remains unrealistic, unless the $1000 \mathrm{hPa}$ wind field is applied instead of the higher level one. The main reason for this feature is the more zonal pattern of the wind velocity in the $850 \mathrm{hPa}$ field, where orographic influences are rather small. Those influences, in terms of katabatic and barrier winds, however, seem to be decisive for realistic ice thickness distributions (see also Schwerdtfeger, 1979), making it necessary to employ the lower-level wind fields. Since the wind field is less predetermined by the specified surface boundary conditions of the NWP model than the temperature and humidity fields, this measure should be less critical.

The model results indicate that the parameterizations in the coupled SI-OML-ABL model have to be readjusted in order to make them reasonable. Assuming that the parameters of the SI-OML model are adequate, the sensitivities of several ABL model parameters were analyzed. It will be shown in a subsequent publication that the results can be improved, for example, by raising the roughness lengths over ice and water, and by increasing the thermally induced turbulence (buoyancy).

\section{ACKNOWLEDGEMENTS}

W.D. Hibler III, P. Lemke, W.B. Owens and C. Koch are thanked for placing their models at my disposal, P. Lemke, M. Heimann and K. Herterich for comments on an earlier version of the paper, H. Schriever for typing the manuscript and M. Grunert for drawing the figures. Thanks are also due to the Deutscher Wetterdienst (DWD), Offenbach, for providing the analyses of the ECWMF, and to R. Schnur for preprocessing these data. This work was partially supported by the Sonderforschungsbereich (SFB) 318 and the Max-Planck-Institut für Meteorologie, Hamburg.

\section{REFERENCES}

Gloersen, P. and W.J. Campbell. 1988. Variations in the Arctic, Antarctic, and global sea ice covers during 19781987 as observed with the Nimbus 7 scanning multichannel microwave radiometer. 7. Geophys. Res., 93(C9), 10,666-10,674.

Hellerman, S. and M. Rosenstein. 1983. Normal monthly wind stress over the world ocean with error estimates. $\mathcal{F}$. Phys. Oceanogr., 13, 1093-1104.
Hibler, W.D., III. 1984. The role of sea ice dynamics in modeling $\mathrm{CO}_{2}$ increases. In Hansen, J.E. and $\mathrm{T}$. Takahashi, eds. Climate processes and climate sensitivity. Washington, DC, American Geophysical Union, 238253. (Geophysical Monograph 29.)

Hibler, W.D., III, and S.F. Ackley. 1983. Numerical simulation of the Weddell Sea pack ice. F. Geophys. Res., 88(C5), 2873-2887.

Koch, C. 1988. A coupled sea ice-atmospheric boundary layer model. Part I. Description of the model and 1979 standard run. Beiträge zur Physik der Atmosphäre, 61(4), 344-354.

Lemke, P. 1987. A coupled one-dimensional sea ice-ocean model. J. Geophys. Res., 92(C12), 13,164-13,172.

Lemke, P., W.B. Owens, and W.D. Hibler, III. 1990. A coupled sea ice-mixed layer-pycnocline model for the Weddell Sea. J. Geophys. Res., 95(C6), 9513-9525.

Owens, W.B. and P. Lemke. 1990. Sensitivity studies with a sea ice-mixed layer-pycnocline model in the Weddell Sea. 7. Geophys. Res., 95(C6), 9527-9538.

Schwerdtfeger, W. 1979. Meteorological aspects of the drift of ice from the Weddell Sea toward the midlatitude westerlies. F. Geophys. Res., 84(C10), 6321-6328.

Stössel, A. 1990. Sea ice simulation in the Southern Ocean including vertical boundary layer interactions. In Johannessen, J.A., P.M. Haugan, and W.B. Owens, eds. Regional and Meso-scale Modeling of Ice Covered Oceans, Solstrand Fjord Hotel, 5200 Os, Norway, 23-27 October 1989. Workshop proceedings. Bergen, Nansen Remote Sensing Center, 157-161. (NRSC Conference Report 3.)

Stössel, A., P. Lemke, and W.B. Owens. 1990. Coupled sea ice-mixed layer simulations for the Southern Ocean. $\mathcal{F}$. Geophys. Res., 95(C6), 9539-9555.

Taljaard, J.J., H. van Loon, H.L. Crutcher, and R.L. Jenne. 1969. Climate of the upper air. I. Southern Hemisphere. Vol. 1. Temperatures, dew points and heights at selected pressure levels. Washington, DC, U.S. Naval Weather Service. (NAVAIR 50/1C/55.)

Trenberth, K.E. and J.G. Olson. 1988. ECMWF global analyses 1979-1986: circulation statistics and data evaluation. Boulder, CO, National Center for Atmospheric Research. (NCAR Technical Note TN-300.)

Trenberth, K.E., J. G. Olson, and W.G. Large. 1989. $A$ global ocean wind stress climatology based on ECMWF analyses. Boulder, CO, National Center for Atmospheric Research. (NCAR Technical Note TN-338.)

Wadhams, P., M.A. Lange, and S.F. Ackley. 1987. The ice thickness distribution across the Atlantic sector of the Antarctic ocean in midwinter. F. Geophys. Res., 92(C13), 14,535-14,552.

The accuracy of references in the text and in this list is the responsibility of the author, to whom queries should be addressed. 